\title{
Platelet depletion and severity of streptococcal endocarditis
}

\author{
Lawrence Dall MD, Todd Miller MD, Betty Herndon PhD, Ireneo Diez MD, Michelle Dew BS
}

\begin{abstract}
L Dall, T Miller, B Herndon, I Diez, M Dew. Platelet depletion and severity of streptococcal endocarditis. Can J Infect Dis 1998;9(6):359-366.
\end{abstract}

OBJECTIVE: To evaluate the importance of thrombocytopenia in streptococcal endocarditis using an animal model. DESIGN: A model of human septic endocarditis was established in rats (polyethylene catheters across the aortic valve and administration of Streptococcus sanguis, $5 \times 10^{7}$ colony forming units [cfu] intravenous). Thrombocytopenia at four levels was produced by antiplatelet serum. Secondary methods of producing thrombocytopenia were also evaluated. At sacrifice ( $96 \mathrm{~h}$ after platelet depletion and $72 \mathrm{~h}$ after infection), vegetations were removed, weighed, diluted, plated and counted. Potential mechanisms of the dose-response relationship between vegetation density and platelet count were evaluated.

SETTING: Controlled research laboratory experiments.

POPULATION STUDIED: Animal models of streptococcal endocarditis.

MAIN RESULTS: The bacterial density of the aortic valve vegetations significantly increased as the platelet count decreased $(\mathrm{P}=0.0007)$. In severely thrombocytopenic animals (two-dose antiplatelet serum), data suggest increased vegetation embolism. Platelet depletion, which was minimal with chemical methods, was produced most effectively by antithrombocyte serum. Platelet surfaces in endocarditis were found to express elevated CD62p proteins $(72.7 \%$ endocarditis, $34.7 \%$ control). Platelet protein fractions were evaluated in vitro by both streptocidal $(\mathrm{P}=0.19)$ and phagocytosis-stimulating assays. Platelet presence in mature aortic valve vegetations averaged only about $2 \%$.

CONCLUSIONS: In platelet depletion experiments using a rat model, a dose-response relationship of peripheral circulating platelet depletion to aortic valve vegetation density was found. The mechanism relating thrombocytopenia to endocarditis severity remains unresolved.

Key Words: Animal model, Bacterial endocarditis, Platelet

\section{Thrombocytopénie et gravité de l'endocardite streptococcique}

OBJECTIF : Évaluer l'importance de la thrombocytopénie dans l'encocardite streptococcique à l'aide d'un modèle animal. MODÈLE : Un modèle d'endocardite septique humaine a été établi chez des rats (cathéter de polyéthylène traversant la valvule aortique et administration de Streptococcus sanguis $5 \times 10^{7}$ unités formant colonie [UFC] i.v.). La thrombocytopénie a été produite à quatre niveaux par un sérum antiplaquettaire. Des méthodes secondaires pour produire une thrombocytopénie ont également été réévaluées. À l'autopsie ( $96 \mathrm{~h}$ après la thrombocytopénie et $72 \mathrm{~h}$ après l'infection) des végétations ont été retirées, pesées, diluées, mises en culture et comptées. Les mécanismes potentiels du lien dose-réponse entre la densité des végétations et la numération plaquettaire ont été évalués.

CONTEXTE : Expériences contrôlées dans un laboratoire de recherche.

POPULATION ÉTUDIÉE : Modèles animaux d'endocardite streptococcique.

PRINCIPAUX RÉSULTATS : La densité bactérienne des végétations de la valvule aortique a significativement augmenté à mesure que la numération plaquettaire diminuait $(\mathrm{p}=0,0007$ ). Chez les animaux gravement thrombocytopéniques (sérum antipla-

voir page suivante

Section of Infectious Diseases, School of Medicine, University of Missouri-Kansas City, Kansas City, Missouri Correspondence: Dr Betty Herndon, Gold 5 Lab, UMKC School of Medicine, 2411 Holmes, Kansas City, Missouri 64108.

Telephone 816-235-1904, fax 816-235-5194, e-mail bherndon@cctr.umkc.edu Reprints: Dr Lawrence Dall, Gold 5 Unit, UMKC School of Medicine, 2411 Holmes, Kansas City, Missouri 64108

Received for publication December 8, 1997. Accepted March 4, 1998 
quettaire en deux doses), les résultats suggèrent un accroissement de l'embolie due aux végétations. La thrombocytopénie, qui a été minime avec les méthodes chimiques, a été produite plus efficacement par sérum antithrombocyte. Les surface plaquettaires dans l'endocardite ont exprimé une élévation des protéines CD62p (72,7 \% des endocardites, 34,7\% des témoins). Les fractions de protéines plaquettaires ont été évaluées in vitro lors d'essais streptocides $(p=0,19)$ et stimulant la phagocytose. La présence des plaquettes dans aux végétations à maturité de la valvule aortique se chiffrait en moyenne à $2 \%$ seulement.

CONCLUSION : Dans des expériences de thrombocytopénie, à l'aide d'un modèle murin inédit, un lien dose-réponse a été confirmé entre l'épuisement des plaquettes périphériques circulantes et la densité des végétations sur la valvule aortique. Les mécanismes permettant d'établir un lien entre la thrombocytopénie et la gravité de l'endocardite restent à élucider.

$\mathbf{I}_{\mathrm{n}}^{\mathrm{n}}$ nfectious endocarditis continues to be a significant clinical problem (1), and an increasing number of deaths have been related to its cause. In long term studies, the morbidity and mortality rate of endocarditis has shown to range from $20 \%$ to $35 \%$ (2-5). The University of Alberta, Edmonton, Alberta alone reported 135 cases of endocarditis in a nine-year study, and the University of Ottawa Heart Institute, Ottawa, Ontario reported a mortality rate of $28 \%$ to $29 \%$ for patients with endocarditis following valve replacement $(5,6)$. Our study, an animal model of this important infectious process, was designed to analyze the function of platelets during the initiation and progression of bacterial endocarditis.

During the initiation of bacterial endocarditis, organisms are trapped in a platelet-fibrin clot and perpetuate attachment to the heart valves. Later clinical features, such as embolism, or the overall vegetation size and mobility may also be platelet related. McGraw et al (7), Miller et al $(8)$ and others $(9,10)$ have studied the role of platelets in bacterial endocarditis initiation, progression and outcome, but that role remains unclear. The platelet-aggregating capacity of streptococcal strains has been seen as a virulence factor in endocarditis (11-13), with aggregation-inducing bacteria causing a more severe course of endocarditis than nonaggregating strains do (14). Animal models have shown the necessity of normal platelet function for development of endocarditis (15), and even in vitro models of endocarditis suggest a role for the coagulation system (16). On the other hand, it has been suggested that platelets may lessen endocarditis severity through enhancement of phagocytosis or by platelet microbicidal protein $(9,14$, $17,18)$. The early efforts of McGraw et al (7) with platelet depletion in a rodent model appeared to back the hypothesis that platelets were host-protective. A rabbit endocarditis model demonstrated smaller, more dense vegetations following platelet depletion (9), although the mechanism was unclear.

The relationship of platelets to the initiation and perpetuation of bacterial endocarditis remains equivocal. Several questions arise. Among them, will platelet depletion affect the course of endocarditis in the rodent model? Demonstration of the phenomenon in multiple species would suggest a fundamental concept. If platelet depletion affects the course of endocarditis, will it do so quantitatively in a dose-response experiment, allowing a causal relationship to be drawn between the treatment and the response? Which platelet-streptococcal interaction is likely to be involved? Studies over several years correlate streptococcal exopolysaccharide with endocarditis severity (19-22). How do platelets relate to those findings?

To answer these questions, experiments using a rat model of endocarditis were performed following multiple levels of platelet depletion. The commercial availability of both antirat thrombocyte sera and specific rat cell-surface antisera for flow cytometry provides a particular advantage to the rat model. Vegetation weight and number of bacteria per unit weight (density $\log _{10}$ [colony forming units $\left.\{\mathrm{cfu}\} / \mathrm{g}\right]$ ] were measured. In this model, the degree of platelet depletion was correlated with increased bacterial density in vegetations. Vegetation weight changed significantly in only the highest dose group. Mechanisms of the proposed protective influence of platelets were investigated by examining antistreptococcal activity of thrombin-stimulated platelet protein. Initial efforts investigating the presence of carbohydrate-binding molecules on the surface of endocarditis-activated platelets are reported.

\section{MATERIALS AND METHODS}

Animal model: The University Animal Care and Use Committee, University of Missouri-Kansas City, Kansas City, Missouri approved the modification of the methods (23) used to produce endocarditis in 280 to $315 \mathrm{~g}$ Sprague-Dawley rats (SASCO, Nebraska). Briefly, polyethylene sleeves (Intramedic PE-10, Clay Adams, Maryland) over sterile 32-gage hypodermic tubing were inserted into the left ventricular lumen via the right common carotid artery of rats anesthetized with ketaminexylazine. The stainless steel insert was removed upon correct placement, and the polyethylene sleeve was sutured in place, remaining until necropsy to assure correct placement. Platelets were depleted at this point, as described below, to preclude development of sterile vegetations before institution of bacteremia. About $20 \mathrm{~h}$ after cannula implantation, $0.5 \mathrm{~mL}$ containing $5 \times 10^{7}$ Streptococcus sanguis ( $16 \mathrm{~h}$ growth, saline suspended) was administered via the tail vein. (This isolate from human endocarditis is a platelet-aggregating strain [24]). Animals were killed by exposure to excess halothane atmosphere three days after bacterial challenge, and blood for platelet studies was taken from the heart immediately. Additional blood (heart or dorsal aorta) was drawn for smears, blood counts, and qualitative or quantitative culture. Hearts with cannulas in place were removed, placed in tissue culture cell-wells and necropsied in sequence under a $12.5 \times$ microsurgical scope (Carl Zeiss fiber optic illuminator model 310187, Carl Zeiss Inc, New York). All vegetations adherent to valve leaflets were aseptically excised and added to preweighed sterile bags, which were weighed again on an analytical balance. The difference in weight was taken as the vegetation weight. Each vegetation was then macerated in the bag with $1 \mathrm{~mL}$ sterile saline, and serial dilutions were made and plated to blood agar. Bacterial vegetation counts were made at $48 \mathrm{~h}$, and $\log _{10}$ bacteria/g of vegetation calculated for each animal.

Platelet counts: Antithrombocyte efficacy was determined at necropsy and in rats that did not undergo surgical interven- 
tion. Platelet counts were made on whole blood using three manual readings in an S-plus STKR Coulter Counter (Florida), instrumentation which allowed exact counts outside normal ranges, and furnished total red and white blood cell counts. Differential white counts were performed on Wright's stained blood smears. Spleens from some groups were quantitatively cultured to determine bacterial clearance in thrombocytopenia.

Antiplatelet serum in endocarditis: Platelet counts were effectively dropped by intraperitoneal administration of rabbit antirat-thrombocyte serum (absorbed, Accurate Chemical \& Scientific Corporation, New York). Immediately postcannulation, $0,0.25,0.375,0.5$ or $0.75 \mathrm{~mL}$ polyclonal antithrombocyte serum was administered. The no antiserum group received sterile-filtered normal rabbit serum (NRS) to control for the intraperitoneal injection trauma at a dose equal to the antithrombocyte serum administered for that experiment. Each endocarditis experiment included four to eight animals at a selected dose, run as a group with either another dose level or NRS endocarditis controls. Endocarditis trials were also performed on rats given two doses of antirat platelet serum, which lowered the platelet count by $95 \%$ to $99 \%$. These animals were given $0.75 \mathrm{~mL}$ intraperitoneally at the time of cannula implantation and another $0.75 \mathrm{~mL}$ at the time of streptococcal administration (two-dose group, $\mathrm{n}=15$ ).

Partial platelet depletion studies: Endocarditis trials were performed on groups of animals receiving partial platelet depletion and solvent control. These studies investigated whether widely variant methods of platelet depletion would produce an effect on endocarditis similar to that of platelet depletion by antithrombocyte serum. Partial platelet depletion was achieved by administration of a natural venom product with antiplatelet component, Agkistron piscivorus leukostoma venom (30 $\mathrm{g} / \mathrm{kg})$, to test rats at the time of cannula insertion. Cancer chemotherapy agents that deplete platelets in man, mithramycin and tetramethylpyrazine, were also studied in small groups. Solvent controls received endocarditis cannulas and streptococci. Additional groups were run for histopathology, spleen culture and evaluation of acute blood counts.

Histopathology and quality control: The standard end-point in quantification of endocarditis vegetation is $\log _{10}[\mathrm{cfu} / \mathrm{g}]$. In thrombocytopenic rats, it was considered possible that the platelet portion of the vegetation mass could be changed, producing an aberrant value for bacterial count per unit weight. To evaluate for this possibility, vegetations from sterile, standard model and thrombocytopenic rats were separated as usual from the valves, embedded, sectioned and stained. Fibrin (Weigert's), bacteria /glycocalyx (periodic acid and Giemsa, Missouri), platelets (immunohistochemical stain) and hematoxylin and eosin were used to stain for elements of the vegetations. Periodic acid and platelet-stained slides were scanned, and the percentage of high-power field $(400 \times)$ staining was quantified (Quantiscan, Cambridge, United Kingdom) for bacsteria and platelets in similar areas of the same vegetation blocks.

Thrombin-activated platelet-streptococcal assays: A protein was prepared from thrombin-induced rat platelets following published methods (25), which was then precipitated and separated by molecular-weight cutoff centrifugation. The filtrate below $10 \mathrm{kDa}$ with a heavy $8.1 \mathrm{kDa}$ band on electrophoresis was used in physiological quantities (up to $26.1 \mathrm{~g} / \mathrm{mL}$ ) in bacterial killing assays (26) in $10 \%$ rat serum enriched tryptic soy broth in the presence and absence of neutrophils. Serial dilutions of test samples were plated after incubation of 1 or $2 \mathrm{~h}$. Endocarditis-strain streptococcal killing by the platelet protein was compared with platelet protein the killing of a Bacillus subtilis strain reported to be susceptible (25).

Endocarditis versus control rat platelets and CD62p reactivity: Platelets were isolated from advanced endocarditis and control rat blood (with and without cannulas) taken by cardiac puncture under halothane at sacrifice. Platelet isolation used centrifugation $(2000 \times g)$, containers and solution (cold tyrodes) that consistently yielded unactivated cells in the FACScan histogram of untreated rats. Fifty mircolitres of a $2 \times 10^{8} / \mathrm{mL}$ solution of washed platelets suspended in tyrodes with $10 \%$ goat serum was allowed to react for $30 \mathrm{~min}$ with $15 \mathrm{~mL}$ undiluted antirat CD62p (PharMingen, California). Platelets were washed once in cold phosphate buffered saline (PBS) and the supernatant removed. Five microlitres undiluted secondary antibody, goat antirabbit immunoglobulin G fluorescein isothiocyanate (FITC) conjugate (Becton Dickinson, California) was added to each sample and incubated in the dark for 30 min. Platelets were washed once in cold PBS, resuspended in $1 \mathrm{~mL}$ of $1.0 \%$ paraformaldehyde to prevent further activation, and were read in a Becton Dickinson FACScan flow cytometer. Gating controls used test platelet samples with only FITC-labelled secondary antibody added. Ten to twenty thousand events from each sample were counted. In other tests, forward and right angle light scatter for FITC intensity was collected with ungated acquisition. Samples were collected and analyzed using Becton Dickinson software.

Statistics and sample sizes: The experiments used 31 animals for venom or chemical depletion and 78 for the doseresponse antiplatelet serum studies. Twelve additional rats were used in pilot testing to quantify platelet response to antisera, 15 additional rats with endocarditis were used to pilot test a two-dose antiserum regimen, and 15 rats with endocarditis were used in spleen culture and vegetation histopathology. Twelve (six with endocarditis and six without) were used as platelet donors in the CD62p testing reported here. The population sizes were based on the in vivo response to the antiserum, without endocarditis. Based on a similar response with endocarditis, with a beta error of 0.20 and a two-tailed alpha error of 0.05 , it was determined that statistical significance could be obtained with the population sizes used.

Mann-Whitney testing was used following the Kruskal Wallace analysis if more than two groups were compared initially. Log-transformed data, the vegetation bacterial counts, were analyzed by ANOVA and Student-Newman-Keuls post-tests.

\section{RESULTS}

Platelet depletion: Control rats have high platelet counts, $1300 \times 10^{3} / \mathrm{L}$ is normal. Two $0.75 \mathrm{~mL}$ intraperitoneal injections of rat antiplatelet serum reduced the counts in some animals to as low as $7 \times 10^{3} / \mathrm{L}$, and in these platelet-depleted 
TABLE 1

Platelet counts in rats: Effect of antithrombocyte treatment

\begin{tabular}{lccc}
\hline $\begin{array}{c}\text { Hours after } \\
\text { antiserum* }\end{array}$ & $\mathbf{0 . 5} \mathbf{~ m L}$ & $\mathbf{0 . 7 5} \mathbf{~ m L}$ & $\mathbf{1 . 5} \mathbf{~ m L}$ \\
\hline 2 & ND & 5.78 .9 & ND \\
24 & ND & 14945.1 & 29.825 .4 \\
72 & 34185.5 & 202141.4 & 41.228 .8 \\
(No antiserum) & & $(1025 \pm 419.3)$ & \\
\hline
\end{tabular}

*Antirat thrombocyte serum absorbed with packed rat erythrocytes (Accurate Chemical \& Scientific Corp, New York). Platelets were counted in whole rodent blood in an S-plus STKR Coulter Counter (Florida) using manual readings in triplicate. Two rats measured at $1 \mathrm{~h}$ after a second administration of $0.75 \mathrm{~mL}$ antiplatelet serum had counts under 10,000. ND No data

animals, the effect on aortic valve vegetations was seen. Table 1 presents average platelet counts at sacrifice of endocarditis model rats, including both platelet-suppressed and unsuppressed (NRS) groups. Administration of mithramycin and tetramethylpyrazine as antiplatelet agents to rodents (data not shown) reduced their platelet counts by $12 \%$ and $32 \%$, respectively. Agkistrodon piscivorus leukostoma venom $(30 \mathrm{~g} / \mathrm{kg})$ as an antiplatelet agent produced decreases in platelet counts of $12 \%$ to $52 \%$. In the venom experiments, a small increase in aortic vegetation density occurred in treated animals, $6.44 \pm 1.05 \log _{10}[\mathrm{cfu} / \mathrm{g}]$ compared with 6.11 .3 in paired solvent controls, $n=8$ and $n=16$, respectively. Two doses of antirat serum depleted platelets to less than $5 \%$ of the normal count Depletion to $50 \%$ and $80 \%$ of the normal level seems to produce the most effect on vegetation in this model. Efficacy of the antiplatelet serum (Table 1) was mostly evaluated by blood samples at necropsy in the experimental animals $96 \mathrm{~h}$ after administration in the single-dose animals.

In a recent 20-animal experiment, red blood cell counts following antiplatelet serum were $6.262 .1 \times 10^{6} / \mathrm{L}$, and total white cell count $6.653 .4 \times 10^{3} / \mathrm{L}$. Red blood cell counts are somewhat low (normal is 7.2 or above), but white blood cell counts are in the normal range following antiplatelet serum administration. The antirat thrombocyte serum, when tested in vitro had an agglutinating titre of 1:2048 for platelets and contained no in vitro red blood cell agglutinating activity.

Endocarditis severity and platelet depletion: Heart valve vegetations from animals receiving antiplatelet serum showed significantly greater bacterial density than NRS endocarditis controls. The bacterial density $\left(\log _{10}[\mathrm{CFU} / \mathrm{g}]\right)$ in heart valve vegetations from antiplatelet-dosed and endocarditis controls is illustrated in Figure 1. Rats administered high doses of antiserum $(0.75 \mathrm{~mL}, \mathrm{n}=14)$ had vegetations with significantly greater bacterial density than lower dosed and control animals. The progressively lower dosed animals $(0.5 \mathrm{~mL}, \mathrm{n}=34$ and $0.375 \mathrm{~mL}$ or $0.25 \mathrm{~mL}, \mathrm{n}=14$ ) had higher platelet counts and significantly fewer bacteria per unit weight in the vegetations. No antiserum (NRS) endocarditis rats $(n=16)$ had lower bacterial density $\left(\log _{10}[\mathrm{cfu} / \mathrm{g}]\right)$ in their vegetation than any platelet-reduced group $(\mathrm{P}<0.01$, Student-Newman-Keuls test).

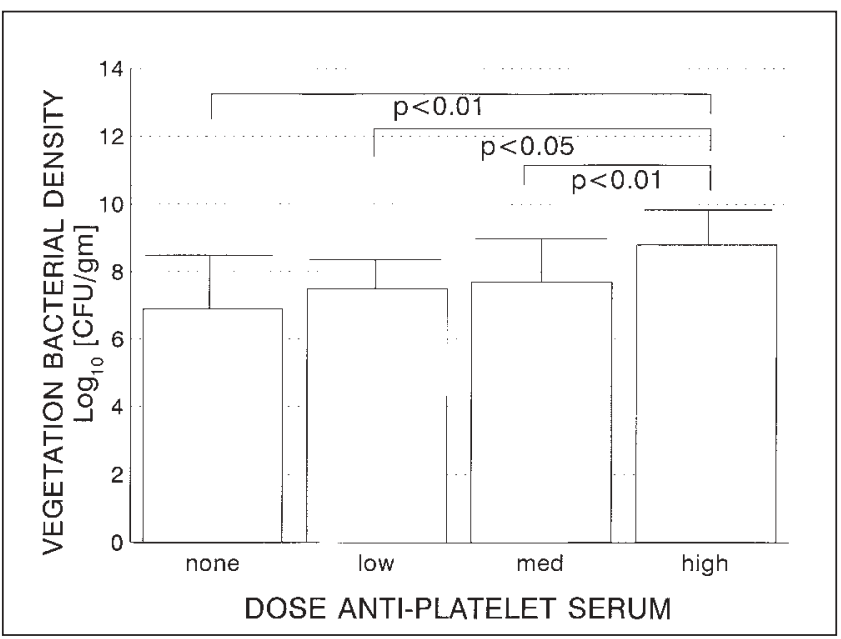

Figure 1) Bacterial endocarditis vegetations with antiplatelet serum administration. Bacterial density (log 10 [colony forming units $\{c f u\} / g r a m$ vegetation weight]), with standard deviation, is presented at different doses of antiplatelet serum in the rat model of endocarditis. Significance shown between groups was calculated by ANOVA and Student-Newman-Keuls multiple comparisons post-test. No dose Received no antiplatelet serum but was injected with a volume of normal rabbit serum equal to the dose received by antiplatelet animals run concurrently (6.9 1.1, $n=16)$; Low dose Received antiserum intraperitoneal 0.25 and $0.375 \mathrm{~mL}(7.51 \pm 0.67, n=14)$; Med dose Received $0.5 \mathrm{~mL}(7.75 \pm 1.04, n=34)$; High dose $0.75 \mathrm{~mL}(8.76 \pm 0.8$, $n=14)$.

Table 2 contains data in which high dose antiplatelet serum was administered on days 1 and 2 to rats with endocarditis, and the weight of their vegetations were compared with a concurrent endocarditis group receiving control serum. The group receiving two injections of antirat platelet serum exhibited very low platelet counts and signs of profound thrombocytopenia. Aortic valve vegetations at $72 \mathrm{~h}$ in the two-dose group exhibited both extremes of size, either very large or much smaller than usual. Bacterial density in the vegetations of these animals was consistently high (Table 2).

Quantitative spleen culture was performed in the thrombocytopenic and standard endocarditis animals. Antiplatelettreated rat spleens $(n=8)$ weighed $0.8160 .39 \mathrm{~g}$ and contained $\log 2.2 \log 2.52$ streptococci per spleen. Standard model endocarditis rats given NRS $(n=7)$ had spleens weighing $0.940 .26 \mathrm{~g}$, with $\log 3.7 \log 3.93$ streptococci. The difference is significant (Mann-Whitney analysis on untransformed data) $(\mathrm{P}=0.03)$. Spleen culture of rats given two doses of antiplatelet serum (data not shown) produced bacterial counts similar to controls ( $\log 3$ to 4). This suggests that either the spleen is trapping streptococci from the initiating dose more efficiently in thrombocytopenia or vegetations from these animals embolized more readily than in the usual model.

Histopathology and quality control: Additionally, this study performed quantitative immunochemical staining on aortic valve vegetations to determine the contribution of platelets to vegetation weight. Both this study and the works of others quantify endocarditis occurrence and severity as $\log _{10}$ [cfu/g], bacterial vegetation density. Depletion of circulating platelets 
TABLE 2

Effects on streptococcal endocarditis model of two-dose antithrombocyte treatment

\begin{tabular}{|c|c|c|c|c|}
\hline \multirow[b]{2}{*}{ Treatment } & \multirow{2}{*}{$\begin{array}{c}\text { Bacterial } \\
\text { density } \\
\log _{10}[\mathrm{cfu} / \mathrm{g}]\end{array}$} & \multicolumn{2}{|c|}{ Vegetation weight (mg) } & \multirow{2}{*}{$\begin{array}{l}\text { Platelet } \\
\text { count } \\
\times 10^{3} / \mu \mathrm{L}\end{array}$} \\
\hline & & Mean & Median & \\
\hline $\begin{array}{c}2 \times 0.75 \mathrm{~mL} \\
\text { antiserum }\end{array}$ & $8.760 .84 *$ & 10.313 .1 & $1.51^{+}$ & $41.228 .7^{\ddagger}$ \\
\hline $\begin{array}{c}0.75 \mathrm{~mL} \\
\text { control } \\
\text { serum }\end{array}$ & $7.740 .93^{*}$ & $13.89 .4^{+}$ & 11.65 & $800.565 .7^{ \pm}$ \\
\hline
\end{tabular}

* $P=0.01$ (Mann-Whitney) significantly different, $2 \times$ antiserum versus normal rabbit serum. ${ }^{+}$Vegetations in this group were either very small or very large. The median vegetation size for one dose $(0.75 \mathrm{~mL})$ was $13.64 \mathrm{mg}$. The high number of early deaths (eight of 15 before $72 \mathrm{~h}$ ) and disparity in valve vegetation weight suggests large vegetations that embolized. ${ }^{*}$ Measured in survivors at necropsy on day 3 after the final antiserum administration. cfu Colony forming units

- if platelets form a significant part of the final vegetation weight - would change that equation by changing the denominator and would thereby negate perceived significance in vegetation bacterial density. To evaluate this possibility, established $(72 \mathrm{~h})$ vegetations from the standard endocarditis model, $24 \mathrm{~h}$ sterile vegetations and vegetations from thrombocytopenic animals were stained for fibrin, bacteria/glycocalyx, and platelets. In the standard endocarditis animal, stained area per high power field averaged $70.3 \% 1.07 \%$ for periodic acid-stained slides showing the infective streptococci and their surrounding exopolysaccharide, while immunostaining for platelet reactive material on the same vegetations a few microns distant showed $2.12 \% \quad 0.23 \%$ stained area per high power field. It was concluded that the input of platelet-reactive material to the mass of an established vegetation was a minor part of the weight and that the standard method of vegetation quantitation $\left(\log _{10}[\mathrm{cfu} / \mathrm{g}]\right)$ was valid in platelet-depleted animals.

In vitro bacterial killing by platelet protein: Killing assays of the $S$ sanguis isolate from rat endocarditis were performed in vitro in the presence of physiological amounts of the precipitated, low molecular weight fraction of supernatant from thrombin-activated rat platelets. Quantities were calculated based on estimated protein in $80 \%$ of a rat's total platelet count, an amount of circulating platelet loss that is frequently seen with the antithrombocyte serum. The platelet protein produced a $1 \mathrm{~h} 1.92 \log$ kill of a susceptible strain (Bacillus subtilis), indicating the efficacy of the isolated material. Figure 2 displays graphed killing data for the endocarditis-producing isolate of $S$ sanguis. Growth medium with platelet protein (five replications) produced minor increases in streptococcal killing over control, $\mathrm{P}=0.19$ at $1 \mathrm{~h}$ and $\mathrm{P}=0.73$ at $2 \mathrm{~h}$ (ANOVA plus post-hoc tests).

Although the authors' studies (unpublished) suggest that neutrophil depletion has little effect on endocarditis vegetation, other work suggests a role for phagocytic cells in endocarditis host defense (27). To evaluate such an effect, isolated rat neutrophils were incubated in vitro with the platelet pro-

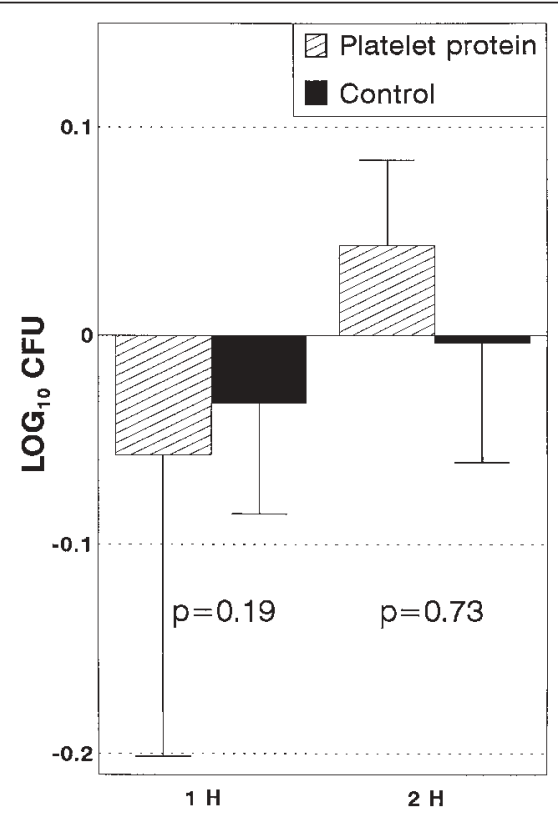

Figure 2) Bacterial killing in vitro by thrombin-stimulated rat platelet protein. Five replications were performed with the endocarditisproducing streptococcus, growth medium and added physiological amounts of thrombin-stimulated platelet protein. Data are graphed as difference in bacterial counts (expressed as $\log _{10}$ [colony forming units] \{cfu\}) from time zero counts. Differences in bacterial killing between control tubes and platelet protein-containing tubes were not significant at 1 or $2 \mathrm{~h}$

tein and the streptococcal isolate producing endocarditis. Streptococcal killing in the presence of neutrophils $(1: 10$, neutrophils:streptococci) was not increased by platelet protein in incubation media. The average log bacterial count with neutrophils alone dropped from 5.6 (beginning) to $5.44 \mathrm{in} 1 \mathrm{~h}$; the count was 5.49 with platelet protein added to neutrophils, and was 5.49 with platelet protein and no neutrophils. At $2 \mathrm{~h}$, streptococcal killing in the presence of neutrophils and platelet protein was at $5.37 \log \mathrm{cfu}$, and that in the tubes with platelet protein alone had increased to $5.7 \log$. These are insignificant streptocidal values ( $\mathrm{P}>0.05$, ANOVA).

Adhesion molecules on platelets in the endocarditis model: Earlier investigations of streptococcal exopolysaccharides (19-22) led the authors to investigate the presence of molecules on the platelet surface that may interact with bacterial surface carbohydrates. It was hypothesized that a difference in streptococcal clearance at initiation may result from a streptococcal-platelet interaction. Because test rats were thrombocytopenic at the time of streptococcal administration and control rats were not, rapid phagocytosis of an in vivo aggregate of streptococcus and platelets (the initiating dose) might explain the eventual difference in vegetation bacterial density. The adhesion molecule CD62p (p selectin), although normally found in the platelet alpha granules, is expressed on the platelet surface when these cells are activated, which occurs with many precipitating triggers. Platelets of endocarditis model rats were compared with the platelets of control rats, 
with and without a cannula across the aortic valve. Platelets from six pairs of rats were incubated with antirat-CD62p and an FITC-labelled secondary antibody and analyzed for fluorescence intensity by flow cytometer. Figure 3 shows two typical histograms, one showing platelets from a control (NRS; with cannula) rat and the other platelets from an endocarditismodel rat. The 10,000 recorded events for each FACScan show increased mean fluorescence and activity by the platelets of the endocarditis rats. Endocarditis rat platelets express significantly more CD62p. On the basis of this staining, one can state that this platelet adhesion molecule, which possesses a carbohydrate ligand, is present at greater levels on platelets of rats with endocarditis compared with rat platelets with cannula alone but no bacteria. Still in question is how this greater expression of a carbohydrate-binding lectin involves the surface ligands of bacteria (or other host cells).

\section{DISCUSSION}

At least two recent reports $(9,10)$, in addition to our abstracts $(7,8)$, observe that a normal platelet count is associated with less severe endocarditis. It is of interest that in clinical reviews the platelet count in endocarditis is rarely if ever reported (28). The current study has correlated platelet depletion and endocarditis severity in a dose-response manner, permitting a causal relationship to be drawn between the agent and the action. In demonstrating this, we verify and extend earlier work on single-level dosage and extend it to a large number of a second species, presenting data that show a sound in vivo relationship between the platelet and the severity of infective endocarditis. Additionally, two potential mechanisms were investigated by which the absence of platelets may allow greater vegetation bacteremia.

In this study, we have eliminated the method of platelet depletion as a contributing variable. Using a broad-acting natural preparation (venom), chemical agents (chemotherapeutic drugs) and the specific antithrombocyte serum, we showed that the platelet count rather than the method of depletion related to streptococcal endocarditis vegetation weight and density. Emphasis on the deleterious effect of depletion (not inactivation) of platelets can also be inferred by the recent work (29), showing that platelet inactivation by acetylsalicylic acid is actually beneficial in the $S$ aureus endocarditis model.

The immunochemical stains on the advanced vegetations re-established information suggested by the classic study of Durack (30). Advanced vegetations in this streptococcal endocarditis model have few recognizable platelets. One might speculate that platelet-microbial interaction at the site of endothelial injury is deleterious to the host: platelets and fibrin gather at sites of valve damage, and streptococci either actively or passively adhere and grow. Activated, circulating platelets, however, may benefit the host because shedding streptococci from the vegetation could be complexed to platelets (CD62p is a carbohydrate lectin) and streptococcal complexes are more rapidly cleared from the circulation than streptococci alone.

Potential mechanisms of the platelet-streptococcal interaction that we report from this endocarditis model produce both
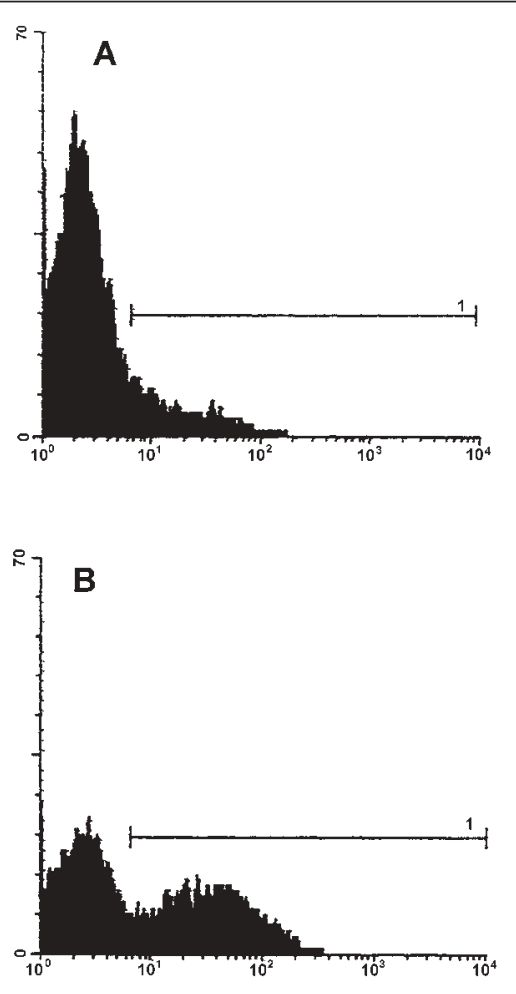

Figure 3) Florescence-activated cell sorter analysis of rat platelet reactivity with antirat CD62p. Top Control rat platelets. Bottom Endocarditis rat platelets, stained with antirat CD62p followed by fluorescein isothiocyanate-labelled secondary antibody. A bar set at $10^{1}$ left and $10^{4}$ right encompasses an average of $72.7 \%$ of the fluorescence on endocarditis rat platelets and, on control rat platelets, an average of $34.7 \%$ of the fluorescence when 10,000 events were recorded on each scan. Significantly more CD62p was present on platelets from endocarditis rats in all pairs tested to date

questions and preliminary answers. Recent studies $(17,18,25)$ have evaluated the antibacterial effects of a platelet microbicidal protein, found as low molecular weight cationic peptides in rabbit platelet alpha granules. Our data, showing increased bacterial density in endocarditis with platelet depletion, could certainly include the possibility of antisstreptococcal activity by platelets in vivo. Our preparations of a protein from rat platelets, however, demonstrated only minor direct streptocidal effects in vitro when added to cultures in physiological amounts. Perhaps the lack of effectiveness of the platelet protein in our rat model relates to exopolysaccharides of the streptococcal isolate used to produce endocarditis. Others have reported inhibition of a bactericidal preparation from rabbit platelets by the addition of short dextran chains (31). It is well known that cultured streptococci shed exopolysaccarides into the medium, and the presence of these dextranlike fragments may inhibit streptocidal activity.

Early work by Yersin et al (27) demonstrated that a profound agranulocytosis significantly slowed spontaneous clearance of streptococcal endocarditis in a rabbit model, bringing into doubt the generally accepted view regarding the absence of cellular host defenses in infective endocarditis. We sought, by in vitro assays of rat platelet protein, to evaluate any effect on 
neutrophil phagocytosis of streptococci by the crude platelet protein. We showed no thrombin-stimulated platelet proteininduced improvement in streptococcal phagocytosis by neutrophils, supporting the generally accepted view.

Our second group of experiments to determine the mode of platelet-host interaction in streptococcal endocarditis was more promising. We saw that, in vivo, an intravenous catheter causes circulating platelets to surface express CD62p, but circulating streptococci cause significantly greater expression. Thus, in endocarditis, there is greater opportunity for streptococcal surface sugars to act as ligands, binding to platelets. Streptococcal-platelet complexes invite more efficient bacterial phagocytosis in vivo. Small changes in streptococcal clearance, early in vegetation initiation, could have profound effects on eventual vegetation size.

\section{CONCLUSIONS}

Dose-response evaluation of platelet depletion in a streptococcal endocarditis model shows data indicating that normal platelet counts benefit the host. Although the mechanisms have not yet been clearly outlined, it is apparent that the

\section{REFERENCES}

1. Rohman S, Erbel R, Darius H, Makowski T, Meyer J. Effect of antibiotic treatment on vegetation size and complication rate in infective endocarditis. Clin Cardiol 1997;20:132-40.

2. Spyrou N, Anderson M, Foale A. Listeria endocarditis: current management and patient outcome - world literature review. Heart 1997;77:380-3.

3. Jault F, Gandykaktch I, Rama A, et al. Active native valve endocarditis: determinants of operative death end late mortality. Ann Thorac Surg 1997;63:1731-41.

4. Siegman I, Kaufman O, Keysary A, Azatkiewicz S, Shalit I. $\mathrm{Q}$ fever endocarditis in Israel and a world wide review. Scand J Infect Dis 1997;29:41-9.

5. Brais M, Bedard J, Goldstein W, Koshal A, Keon W. Ionescu-Shiley pericardial xenografts: follow-up of up to 6 years. Ann Thorac Surg 1985;39:105-11.

6. Sandre R, Shafran S. Infective endocarditis: Review of 135 cases over 9 years. Clin Infect Dis 1996;22:276-86.

7. McGraw J, Herndon B, Suvarna P, Dall L. Effects of reduced platelet number and function of streptococcal endocarditis. American Society for Microbiology 93rd General Meeting. Atlanta, May 16-20, 1993. (Abst B202:92).

8. Miller T, Herndon B, Dall L. Influence of thrombocytopenia on vegetation bacterial density in a rat model of viridans streptococcal endocarditis. FASEB J 1995;9:A521.

9. Sullam PM, Frank U, Yeaman MR, Täuber MG, Bayer AS, Chambers HF. Effect of thrombocytopenia on the early course of streptococcal endocarditis. J Infect Dis 1993;168:910-4.

10. Sande M, Korzeniowki OM, Scheld WM. Factors influencing the pathogenesis and prevention of infective endocarditis. Scand J Infect Dis 1982;31:48-54.

11. Manning JE, Hume EB, Hunter N, Knox KW. An appraisal of the virulence factors associated with streptococcal endocarditis. J Med Micro 1994;40:110-4.

12. Ford I, Douglas CW, Preston FE, Lawless A, Hampton KK. Mechanisms of platelet aggregation by Streptococcus sanguis, a causative organism in infective endocarditis. $\mathrm{Br} \mathrm{J} \mathrm{Haematol}$ 1993;84:95-100.

13. Burnette-Curley D, Wells V, Viscount H, et al. FimA, a major virulence factor associated with Streptococcus parasanguis endocarditis. Infect Immun 1995;63:4669-74.

14. Herzberg MC, MacFarlane GD, Gong K, et al. The platelet interactivity phenotype of Streptococcus sanguis influences the course of experimental endocarditis. Infect Immun 1992;60:4809-18. platelet plays a key role in antimicrobial defense. The clinical importance of this experimental study can be found in the significant relationship between low platelet counts and severity of endocarditis. Clinical application of this information at this time is to preserve platelet numbers during treatment for endocarditis and avoid therapies that lower platelet counts.

Future clinical and experimental studies will, it is hoped, provide further proof that the platelet is part of the host defense against endocarditis and the precise mechanisms through which this occurs. If the platelet has an extensive role in protection of infection by the binding of surface ligands of bacteria, this may change the way that prophylaxis of infection of damaged and prosthetic heart valves is approached.

ACKNOWLEDGEMENTS: This study was supported in part by a grant KS-91G22 from Kansas Affiliates, American Heart Association, Topeka, Kansas, and from the Sarah Morrison Bequest for Internal Medicine, University of Missouri-Kansas City School of Medicine, Kansas City, Missouri (LD). A literature study on the role of platelets in host defense was published while this manuscript was under review (Yeaman MR. The role of platelets in antimicrobial host defense. Clin Infect Dis 1997;25:951-70).
15. Johnson CM, Bowie EJ. Pigs with von Willebrand disease may be resistant to experimental infective endocarditis. J Lab Clin Med 1992;120:553-8.

16. Bancsi M, Thompson J, Bertina RM. Stimulation of monocyte tissue factor expression in an in vitro model of bacterial endocarditis. Infect Immun 1994;62:5669-72.

17. Wu T, Yeaman MR, Bayer AS. In vitro resistance to platelet microbicidal protein correlates with endocarditis source among bacteremic staphylococcal and streptococcal isolates. Antimicrob Agents Chemother 1994;38:729-32.

18. Dankert J, van der Werff J, Zaat SAJ, Joldersma W, Klein D, Hess J. Involvement of bactericidal factors from thrombin-stimulated platelets in clearance of adherent viridans streptococci in experimental infective endocarditis. Infect Immun 1995;63:663-71.

19. Mills J, Pulliam L, Dall L. Exopolysaccharide production by viridans streptococci in experimental endocarditis. Infect Immun 1984;43:359-67.

20. Dall L, Barnes W, Lane L. Enzymatic modification of glycocalyx in the treatment of endocarditis due to viridans streptococci. J Infect Dis 1987;156:736-40.

21. Dall L, Herndon B. Association of cell-adherent glycocalyx and endocarditis production by viridans group streptococci. J Clin Microbiol 1990;28:1698-700.

22. Dall L, Herndon B, Smith R. Reactivity of the glycocalyx of endocarditis-producing viridans group streptococci. Diag Microbiol Infect Dis 1993;17:259-64.

23. Santoro J, Levison ME. Rat model of experimental endocarditis. Infect Immun 1978;19:915-8.

24. Helsel J, Dew M, Herndon B, Dall L. Aggregation of human platelets in the analysis of bacterial involvement in endocarditis. 96th Annual American Society for Microbiology. New Orleans, May 19-23, 1996. (Abst B363:217)

25. Yeaman MR, Puentes SM, Norman DC, Bayer AS. Partial characterization and staphylocidal activity of thrombininduced platelet microbicidal protein. Infect Immun 1992;60:1202-9.

26. Bamberger DM, Fields MT, Herndon BL. Efficacies of various antimicrobial agents in treatment of Staphylococcus aureus abscesses and correlation with in vitro tests of antimicrobial activity and neutrophil killing. Antimicrob Agents Chemother 1991;35:2335-9.

27. Yersin BR, Glauser MP, Freedman LR. Effect of nitrogen mustard 
on natural history of right-sided streptococcal endocarditis in rabbits: role for cellular host defenses. Infect Immun 1982;35:320-5.

28. Patrick WD, Brown WD, Art M, Bowmer I, Sinave CP. Infective endocarditis due to Eikenella corrodens; case report and review of the literature. Can J Infect Dis 1990;1:139-42.

29. Nicolau DP, Marangos MN, Nightingale $\mathrm{CH}$, Qintiliani R. Influence of aspirin on development and treatment of experimental Staphylococcus aureus endocarditis. Antimicrob Agents Chemother 1995;39:1748-51.

30. Durack DT. Experimental bacterial endocarditis. Structure and evolution of very early lesions. J Pathol 1975;115:81-9.

31. Koo S-P, Yeaman MR, Bayer AS. Staphylocidal action of thrombin-induced platelet microbicidal protein is influenced by microenvironment and target cell growth phase. Infect Immun $1996 ; 64: 3758-64$ 


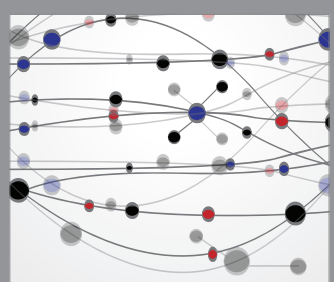

The Scientific World Journal
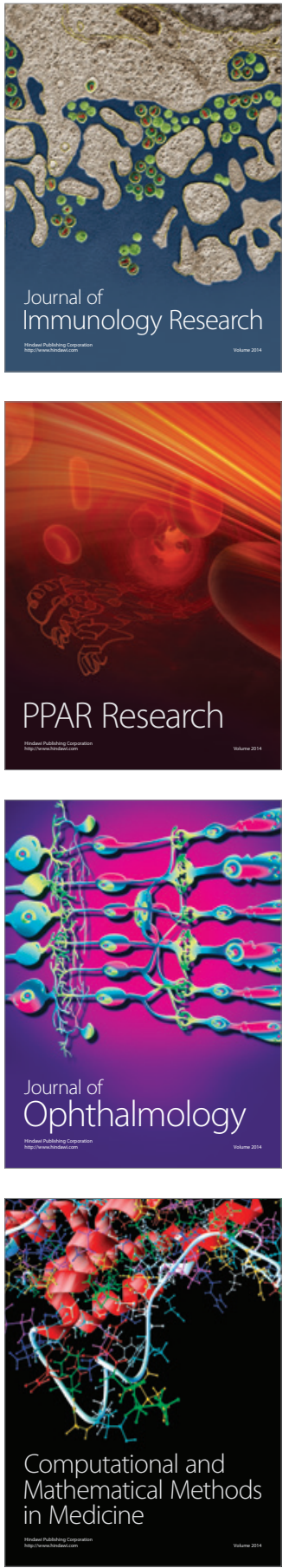

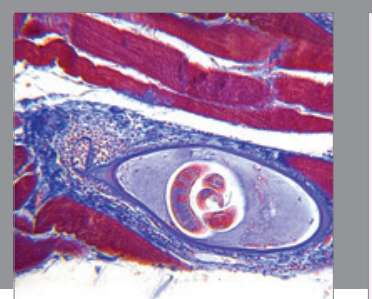

Gastroenterology Research and Practice

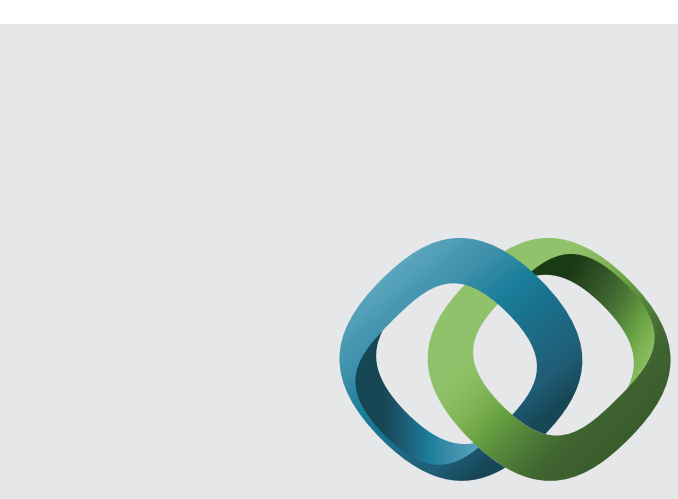

\section{Hindawi}

Submit your manuscripts at

http://www.hindawi.com
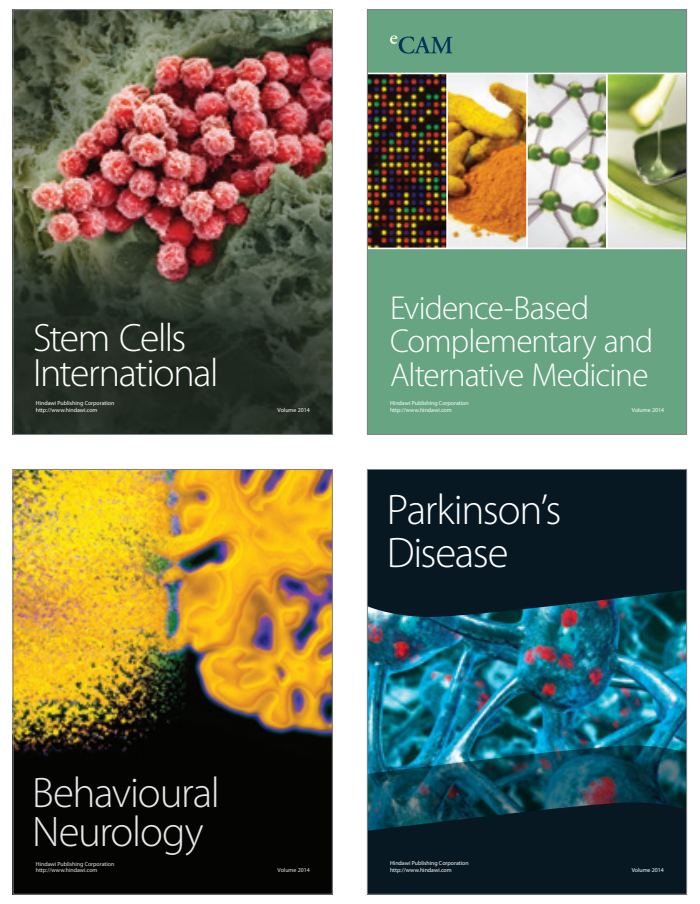
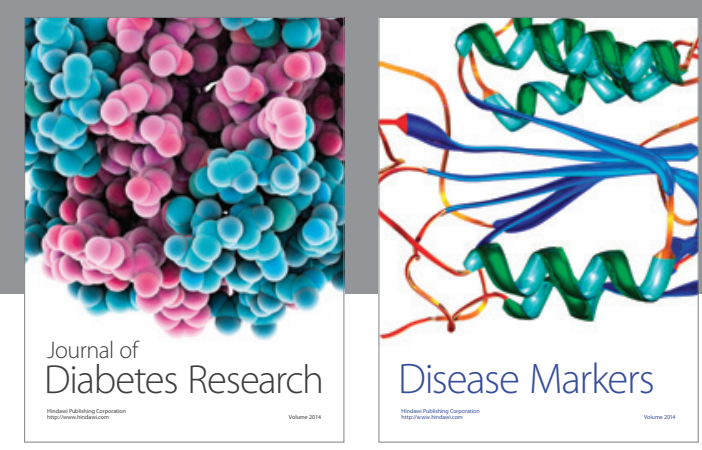

Disease Markers
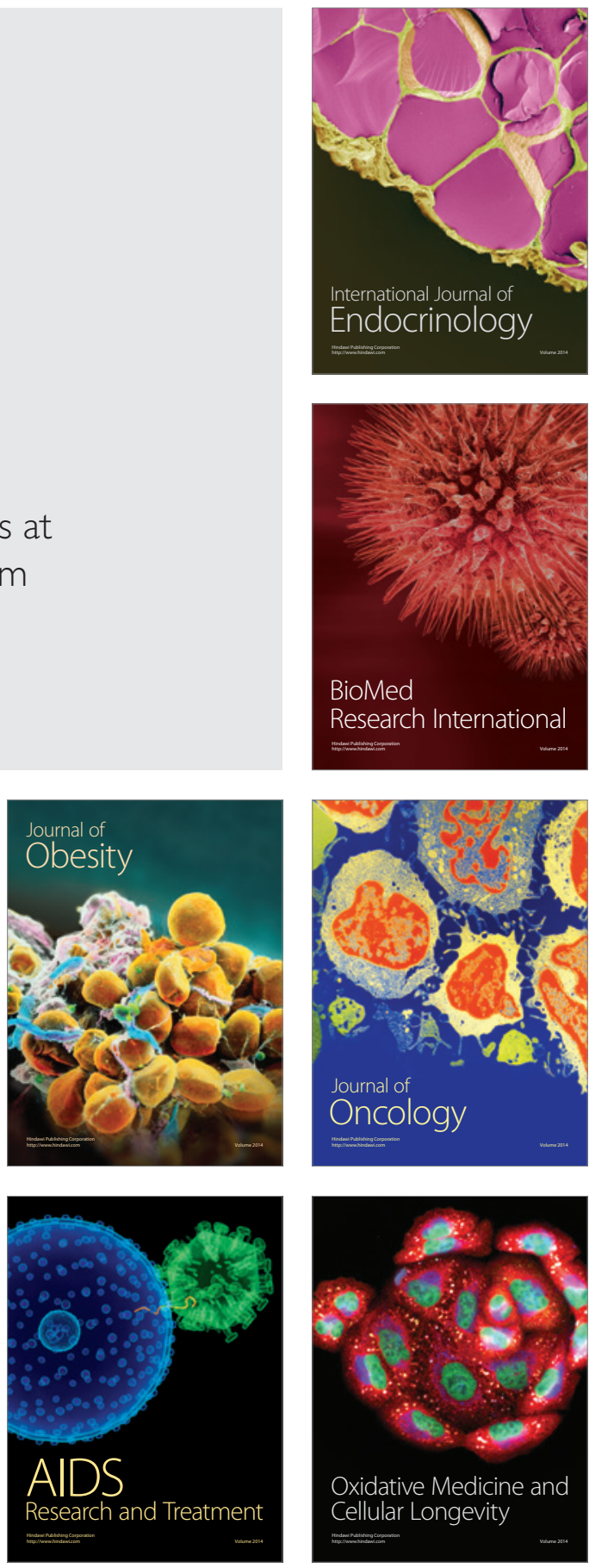